\title{
CONHECIMENTO DE MUNDO POR MEIO DA LEITURA DIGITAL: UM ESTUDO COM UNIVERSITÁRIOS
}

\author{
CONOCIMIENTO DE MUNDO POR MEDIO DE LA LECTURA DIGITAL: UN \\ ESTUDIO CON UNIVERSITARIOS
}

WORLD KNOWLEDGE BY DIGITAL READING: A STUDY WITH UNIVERSITY

Francielle Pereira NASCIMENTO ${ }^{1}$

Sandra Aparecida Pires FRANCO ${ }^{2}$

RESUMO: Na sociedade contemporânea, as práticas humanas estão relacionadas às Tecnologias da Informação e Comunicação (TIC), isto é, estamos vivendo a cibercultura. A educação formal não está isolada do movimento e das transformações ocasionadas pelo acesso e utilização das TIC. Os estudantes do Ensino Superior utilizam os celulares e notebooks na universidade continuamente, tanto para exigências acadêmicas quanto para comunicação e entretenimento. Diante desse contexto, o presente estudo teve como objetivo principal analisar qual conhecimento de mundo a leitura na internet proporciona aos universitários, uma vez que $\mathrm{o}$ ato de ler supera o mero hábito da leitura ou decodificação de palavras, pois, enquanto necessidade humanizadora, permite aos leitores se apropriar da cultura e ter um conhecimento de mundo de modo científico. Como procedimento investigativo foi aplicado um questionário semiestruturado de seis questões com dez estudantes de diferentes cursos de uma universidade privada na região Sul do Brasil. O tratamento dos dados foi qualitativo, baseado na abordagem crítico-dialética. Os resultados coincidiram com uma pesquisa de nível nacional, a qual aponta leituras digitais de formas e conteúdos variados, com ênfase em redes sociais e sites de notícias, e pouco destaque para livros e jornais. A leitura de material acadêmico foi expressa por $100 \%$ dos estudantes, no entanto, sobre o conhecimento de mundo propiciado pelas leituras no suporte tela, as respostas se reduziram às atualizações do mundo, da profisssão e outros, sem a menção de um entendimento crítico e reflexivo da realidade que desperte a necessidade de transformação.

PALAVRAS-CHAVE: Leitura. Conhecimento científico. Internet.

RESUMEN: La sociedad contemporánea, como las prácticas humanas están relacionadas con las Tecnologías de la Información y la Comunicación (TIC), es decir, estamos viviendo a cibercultura. Una educación formal no está aislada del movimiento y las transformaciones ocasionadas por el acceso y uso de las TIC. Los estudiantes del Ensino Superior usan los celulares y los cuadernos en la universidad continuamente, tanto para

1 Pedagoga, mestranda em educação pelo Programa de Pós-Graduação em Educação da Universidade Estadual de Londrina. Membro do projeto de pesquisa "A leitura e sua relação conteúdo, forma e destinatário na Educação Básica".

${ }^{2}$ Prof $^{a}$. do Programa de Pós-Graduação em Educação da Universidade Estadual de Londrina. Coordenadora do projeto de pesquisa "A leitura e sua relação conteúdo, forma e destinatário na Educação Básica". 
las exigencias acadêmicas como para la comunicación y el entretenimiento. Diante desse contexto, o presente estudio tuvo como objetivo principal análisis cualitativo del mundo a la lectura en la Internet permite a los universitarios, una vez que se trata de una supera o mero hábito de la lectura o la descodificación de palabras, Leitores se apropieren de la cultura y el conocimiento del mundo de modo científico. Como el procedimiento investigativo se aplicó en un cuestionario semiestruturado de seis estudios de los estudiantes de diferentes cursos de una universidad privada en la región del Brasil. Tratamiento de los problemas de calidad, basado en la atención crítica y dialética. Los resultados coinciden con una búsqueda de nivel nacional, una calidad de los elementos digitales de formas y contenidos variados, con una red social y sitios de noticias, y un poco de destaque para los libros y los días. A lectura de material acadêmico fue expresado por el $100 \%$ de los estudiantes, sin embargo, sobre el conocimiento del mundo propiciado por las lecturas no soporte de la tela, como las respuestas se redujo a las actualizaciones del mundo, de la profecía y otros, sin una mención de un entendimiento crítico feflexivo de la realidad que desperte una necesidad de transformação.

PALAVRAS CLAVE: Lectura. Conocimiento científico. Internet.

ABSTRACT: In contemporary society, human practices are related to Information and Communication Technologies (ICT), that is, we are living cyberculture. Formal education is not isolated from the movement and transformations caused by access to and use of ICT. Higher education students use cell phones and notebooks at university continually both for academic requirements and for communication and entertainment. In view of this context, the main objective of this study was to analyze which world knowledge reading on the Internet gives university students, since the act of reading surpasses the mere habit of reading or decoding words, as a humanizing need, allows readers to appropriate the culture and to have a scientific knowledge of the world. As a investigative procedure, a semistructured questionnaire of six questions was applied to ten students from different courses of a private university in the southern region of Brazil. The treatment of the data was qualitative, based on the critical-dialectic approach. The results coincided with a nationwide survey, which points to digital readings of varied forms and content, with emphasis on social networks and news sites, and little prominence for books and newspapers. The reading of academic material was expressed by $100 \%$ of the students, however, on the world knowledge provided by the readings in the screen medium, the answers were reduced to the updates of the world, the profession and others, without the mention of a critical understanding and Reflective of reality that awakens the need for transformation.

KEYWORDS: Reading. Scientific knowledge. Internet.

\section{Introdução}

Em cada momento histórico as tecnologias desenvolvidas pelo trabalho humano imaterial e material possibilitaram, além de diferentes vivências, o alcance de metas e objetivos coletivos, o estabelecimento e mediações de relações sociais, práticas cotidianas 
e novos comportamentos, favorecendo o desenvolvimento dos sujeitos. (LALUEZA; CRESPO; CAMPS, 2010, p. 48).

Ao reportar à história, a partir da década de 1970, as Tecnologias da Informação e Comunicação (TIC) permitiram uma revolução do sistema de mídias, uma vez que, com a convergência das telecomunicações e informática, houve o estabelecimento de relações simbólicas entre a sociedade, cultura e as novas tecnologias (LEMOS, 2010; OLIVEIRA, 2011). Após os anos 90, com a popularização mundial da internet e dos meios de comunicação em massa, houve o advento das TIC, que, enquanto produções humanas, fizeram com que novas necessidades do próprio homem fossem criadas para a vida cotidiana, tornando-se recursos indispensáveis a partir de então.

Desse modo, afirma-se que a sociedade atual vive a cibercultura, pois está estruturada pelas tecnologias e as práticas humanas estão relacionadas às TIC. Em meio a essa realidade - de sujeitos autores e atores ativos no acesso e na utilização das TIC e daqueles excluídos, que não tem acesso digital - não é possível separar o homem do seu ambiente material e do mundo material, composto por múltiplos elementos artificiais, resultantes da produção humana. (SANTOS, 2009).

As universidades, assim como outras instituições da sociedade, não está isolada do movimento e das transformações ocasionadas pelo acesso e utilização das TIC. Os estudantes do Ensino Superior da contemporaneidade têm sua vida acadêmica permeada pelo acesso à internet móvel. A utilização dos celulares e notebooks no contexto universitário é contínua, tanto para exigências acadêmicas quanto para comunicação e entretenimento. Seja para acessar, utilizar ou se comunicar, todos têm como necessidade primordial a leitura. Essa atividade tipicamente humana, aprendida no decorrer da vida por meio do desenvolvimento das funções psíquicas superiores, é indispensável no contexto universitário. Entretanto, por ser uma produção humana, os materiais disponibilizados no meio digital possuem uma forma e um conteúdo, uma essência e uma aparência, passíveis de serem apropriadas pelo leitor. As novas e diferentes TIC vêm transformando não só as estruturas e formas das instituições, mas também o conteúdo, a essência das leituras que os estudantes realizam.

Sendo assim, quais materiais os estudantes universitários leem? Qual a essência dessa leitura? Elas são capazes de possibilitar a apropriação do conhecimento científico ou disponibiliza apenas conhecimentos imediatos? Partindo desses questionamentos, o presente estudo teve como objetivo principal analisar qual conhecimento de mundo a 
leitura na internet proporciona aos universitários. Como procedimento investigativo foi aplicado um questionário semiestruturado de seis questões com dez estudantes do Ensino Superior de diferentes cursos de uma universidade privada na região Sul do Brasil. Os desdobramentos e resultados da investigação serão dispostos a seguir.

\section{$O$ ato de ler e a leitura digital}

A capacidade humana de ler é uma forma superior, um avanço qualitativo do homem, resultante do desenvolvimento histórico e cultural da humanidade. (VYGOSTKY, 2007). Entretanto, toda leitura é uma forma psíquica superior? Todo conteúdo lido permite ao homem se desenvolver qualitativamente e ter uma visão crítica e transformadora de mundo?

Levacov (1998) afirmou que a transição do texto impresso para o eletrônico tenderia a criar uma transformação radical na forma de acesso, de leitura e de compreensão da informação, pois, isto implicaria novas maneiras de relação entre sujeitos e objetos do conhecimento. Quase dez anos após a premissa do autor, o crescimento do número de leitores brasileiros é acompanhado pelo aumento do número de pessoas que já usaram a internet.

Neto (2016), em sua análise dos resultados da mais recente pesquisa (4a edição) Retratos da Leitura no Brasil, do Instituto Pró-Livro, indica o crescimento percentual de leitores brasileiros, de 50\% para 56\% de 2011 para 2015. Nessa direção, o autor também demonstra que em 2011, 81 milhões de brasileiros já haviam usado a internet, e em 2015, esse número aumentou para 127 milhões. Outro dado importante é que $81 \%$ dos leitores atuais são usuários da internet, o que o autor considera uma premissa positiva e pedagógica, uma vez que, "os leitores tendem a incorporar tecnologias e fazem uso de todas elas no seu hábito de ler e de viver". (NETO, 2016, p.64).

Nesse sentido, afirmar que as Tecnologias da Informação e Comunicação trazem possíveis "impactos" para a sociedade é um equívoco, pois, tal assertiva considera a tecnologia como um agente autônomo, separado da cultura e dos homens, esses últimos, passivos e regidos por elas. (LEVY, 2010). Ao contrário disso, o autor pondera que as atividades humanas em geral são constituídas de interação entre sujeitos vivos e racionais, entidades materiais, artificiais e naturais e ideias e representações. 
Assim, a educação, ao se deparar com a realidade das TIC, precisa “[...] desenvolver alternativas metodológicas que permitam a construção do conhecimento e o desenvolvimento da autonomia do aprendiz". (ALTOÉ, 2003, p. 438). Afinal, este estudante está imerso em uma sociedade na qual o conhecimento está sendo disseminado em diferentes mídias. Porém, mediante a erupção de recursos tecnológicos e das hipermídias que facilitam a leitura, é valido ressaltar a necessidade de analisar a qualidade de algumas produções disseminadas na internet.

É por intermédio do ato de ler, uma necessidade humanizadora, que se supera o mero hábito da leitura ou decodificação de palavras, uma vez que ele permite aos leitores se apropriar da cultura, de conhecimentos científicos de um espaço e tempo que eles não vivenciaram e que faz parte do arcabouço cultural da humanidade. Em outras palavras, significa ter uma visão de mundo crítica, reflexiva e transformadora.

Manguel (1997) ressalva que o ato de ler é um processo que necessita de uma postura ativa por parte do leitor, pois, é compreendido como um processo discursivo em que autor e leitor são sujeitos produtores de sentidos, homens sociais e históricos. A elaboração do sentido de um texto é influenciada pelos elementos constitutivos do seu ser, ou seja, suas ideologias, pensamentos, valores e conceitos. O promotor da diferença na leitura de um livro é o leitor e não a obra em si. Destarte, não há sentido ou significado do texto antecedente à leitura. Assim, questiona-se: os textos digitais estão proporcionando o ato de ler?

Ao analisar as atividades praticadas na internet, Neto (2016) afirma que 50\% dos usuários (pessoas que acessaram a rede nos últimos três meses) utilizam a internet para acessar ou participar de redes sociais, blogs ou fóruns; a mesma quantidade afirma utilizar para ouvir música. Em relação às atividades de leitura na internet, 52\% afirmaram utilizar a internet para ler notícias e obter informações.

Esses números contrastam com os indicadores sobre a leitura de livros e revistas. Só $16 \%$ leem jornais, $15 \%$ leem livros e 11\% leem revistas. E apenas 19\% dos usuários de internet a utilizam para compartilhar textos e informações sobre livros e literatura em blogs, fóruns e mídias sociais. Nesse sentido, é importante investigar o conhecimento de mundo que está sendo propiciado a esses sujeitos, bem como a especificidade da educação nesse contexto. 


\section{Metodologia}

Em todas as esferas da vida social humana há relações dialéticas, as quais permitem que a sociedade se movimente. Nessa perspectiva, é necessário considerar todas as relações que permeiam um fenômeno para compreendê-lo, pois, a partir de uma particularidade é possível a análise do todo, do concreto, que foi objetivado por intermédio delas. (SÁNCHEZ GAMBOA, 2010).

Portanto, para analisar qual conhecimento de mundo a leitura na internet proporciona aos universitários, foi utilizada a abordagem crítico-dialética com tratamento de dados qualitativo. Por intermédio deste método, foi possível compreender a leitura digital enquanto um recurso presente na vida social dos universitários, ou seja, tem-se a realidade concreta construída historicamente como ponto de partida, não como um elemento isolado, mas que é parte das variadas relações objetivadas que formam o concreto.

O conjunto de procedimentos investigativos foi composto pela revisão bibliográfica, por um questionário semiestruturado e a análise crítica dialética posterior à aplicação. Os participantes da pesquisa foram dez estudantes (gênero feminino e masculino) de diferentes idades que cursam sua primeira graduação, todos de uma universidade privada do norte do estado do Paraná, localizado no sul do Brasil. O critério de seleção dos estudantes aconteceu por conveniência, visto que foram os que se mostraram mais dispostos a contribuir com o estudo.

Eles responderam um questionário semiestruturado mediante o livre consentimento e à garantia do sigilo de identificação. O instrumento foi composto por seis questões, sendo elas: Você costuma realizar leituras pela internet?; Com que frequência?; Que tipo de material você lê?; Qual a essência desses materiais?; Você costuma discutir sobre o que lê em algum desses materiais? Com outras pessoas ou em espaços virtuais? Quais e de que maneira?; Em sua opinião, qual conhecimento de mundo essas leituras digitais te proporcionam?

As respostas dos participantes foram identificadas no decorrer do texto pelas seguintes denominações: E (estudante) e um número (1, 2, 3, etc), as quais se classificam pela ordem da resposta. O tópico a seguir é composto pela análise dos dados coletados, que foi submetida à abordagem crítica-dialética. 
Cabe ressaltar que a pesquisa atendeu a todos os dispositivos da Resolução 246/2012 do Conselho Nacional de Saúde e seus complementares, e foi aprovada pelo Comitê de Ética em Pesquisa da Universidade Estadual de Londrina. Assim, a pesquisa está vinculada ao projeto "A leitura e sua relação conteúdo, forma e destinatário na Educação Básica", sob parecer no 2.038.854, desenvolvida no Programa de Pós-Graduação em Educação da referida universidade.

\section{O conhecimento de mundo dos universitários}

Sabe-se que com as possibilidades que as TIC oferecem, o homem passou de um leitor contemplativo para um leitor imersivo, que pode transmitir a outras gerações por intermédio de um texto publicado na internet as objetivações das quais ele se apropriou. Assim, a cultura contemporânea caracteriza-se pela composição de todas as formações culturais vivenciadas até então, e uma delas é o uso das tecnologias para a leitura. (WEBER; SANTOS; DA CRUZ, 2014).

No entanto, o questionamento impulsionador desse trabalho se debruça sobre qual o conhecimento de mundo que as leituras digitais estão proporcionando aos universitários. Apesar de ser um grupo de dez estudantes, considera-se que eles são parte de uma totalidade, portanto, refletem a essência de um complexo maior, repleto de relações e contradições.

Dos dez participantes desse estudo, $100 \%$ relataram que utilizam a internet como ferramenta para a leitura todos os dias e para algum tipo de material acadêmico, como, por exemplo, artigos em periódicos ou livros digitais. Essa afirmação, em 70\% das respostas, estava acompanhada de outras leituras. Seis estudantes mencionaram a leitura em redes sociais, sites de notícias e entretenimento, muitos deles conhecidos nacionalmente por divulgarem a cada minuto notícias sobre esporte, política, famosos, entre outros. Um estudante afirmou que lê "notícias, fofocas, artigos científicos e curiosidades..." (E2).

Os dados singulares obtidos nesse estudo não diferem muito da totalidade expressa por Netto (2016), já mencionada anteriormente, a qual evidenciou que as atividades mais praticadas na internet pelos brasileiros são as redes sociais, blogs, fóruns e músicas. A respeito especificamente da leitura, os números nacionais ilustram que $52 \%$ dos leitores que leem na internet a usam para ler notícias e obter informações. Quanto à leitura digital 
de jornais, é realizada por $16 \%$, livros por $15 \%$, e revistas por $11 \%$, números baixos quando comparados à leitura de notícias ou sites que fornecem informações em geral.

Nesse ponto, observa-se um destaque nas respostas dos estudantes ao afirmarem que leem materiais acadêmicos, o que não apareceu na pesquisa de âmbito nacional; constata-se um ponto positivo se relacionado à especificidade da educação formal, que segundo Saviani (2013) é produção humana não material, pois produz ideias, conceitos, valores, hábitos e atitudes. De acordo com o autor, "a natureza humana não é dada ao homem, mas por ele é produzida, sobre a base da natureza biofísica" (SAVIANI, 2013, p.13), sendo assim, o papel da educação é de produzir de maneira direta e intencional em cada indivíduo singular a humanidade que é produzida na história, coletivamente pelos homens. Como esse processo ocorre?

Os conteúdos científicos são considerados na perspectiva materialista histórica e dialética como produções humanas, que foram objetivadas pelos homens no decorrer da história por meio do trabalho, uma atividade tipicamente humana que os permite produzir e se produzirem. Eles podem ser objetivados pelo trabalho material ou imaterial do homem, em artigos científicos, obras de arte, obras literárias, entre outros acervos que ultrapassem o imediatismo, o senso comum e a cotidianidade.

O processo educativo tem a especificidade de oportunizar ao aluno, de modo intencional, a apropriação de todo os conteúdos de diferentes áreas, a fim de que ele se humanize, tenha conhecimento acerca da sua realidade e da historicidade das relações e contradições existentes nela. Portanto, diante da leitura acadêmica científica apontada por todos os universitários participantes, evidenciou-se uma possibilidade de visão de mundo ampliada.

Quando questionados sobre "Qual a essência desses materiais" lidos, as respostas se diversificaram e foi mencionado: vídeos sobre história, atualidades, políticas, fofocas, redes sociais, conteúdos relacionados ao curso de Psicologia, música, biografias e notícias sobre atualidades. Essa diversidade de respostas explicita a gama de informações e conteúdos que podem ser encontradas por meio da internet, das mais variadas formas, o que é considerado bom por uma percepção quantitativa. Até porque a utilização da internet como ferramenta para a leitura de material acadêmico mencionada na primeira questão por todos os participantes evidencia uma atividade de busca por conhecimento científico, que auxilia na apropriação dos saberes de sua área e também na realização das tarefas acadêmicas. 
No entanto, diante da pergunta "Você costuma discutir sobre o que lê em algum desses materiais? Com outras pessoas ou em espaços virtuais?" 50\% dos estudantes disseram que sim, e as respostas foram as seguintes: "Sim, com as pessoas em casa, mãe..." (E1); "Sim, sobre conteúdos relacionados ao curso, sobre política, atualidades e mídia em geral." (E2); "Sim, pelo chat do facebook e e-mail (E3)"; "Sim, economia e política para fins de atualização para onde investir novas ideias" (E6); "Geralmente costumo discutir com outras pessoas, mas não em espaços virtuais"(E7). Os outros 50\% afirmaram que não discutem e um ressaltou "Não costumo discutir questões científicas, entretanto, as notícias eu procuro discutir com meus amigos na faculdade, nas redes sociais também.” (E4)

Frente a essa realidade, observa-se que $50 \%$ discutem o que leem e $50 \%$ não. Dos que discutem, $20 \%$ mencionaram espaços virtuais e $30 \%$ outras pessoas. Acerca disso, Giroux (1997) assevera que a educação deve possibilitar que os alunos questionem, debatam sobre o que é lido e apresentado, de modo que eles assumam uma posição de acordo com suas convicções, elaboradas por intermédio do conhecimento que foi apropriado, do seu concreto pensado.

No entanto, essa é uma possibilidade de alteração da realidade, quando a leitura e a escrita estão a serviço da transformação humana, do desenvolvimento do concerto pensado. Por isso, frente aos dados, ressalva-se a necessidade de investigações com esses estudantes que não discutem, problematizando se a leitura está possibilitando que eles se apropriem de algum conteúdo ou não; assim como a qualidade daquelas realizadas pelos que afirmam fazer.

$\mathrm{O}$ ato de ler pode ter função potencializadora de vozes, pois permite ao leitor um conhecimento de mundo sobre sua realidade, de modo a combater possíveis injustiças sociais (MANGUEL, 1997), a medida em que ele atribui significado ao texto, apropria-se de visões de mundo, de objetivações e cultura humana por meio dos seus sentidos, e, assim, eleva as potencialidades das suas funções psíquicas superiores.

Desse modo, a leitura não pode se limitar ao atendimento de necessidades cotidianas imediatas, como por exemplo, a curiosidade por saber o que ocorre na vida de um "famoso", ou com um time. A leitura deve consistir no ato de ler, na possibilidade do homem em se apropriar de conhecimentos científicos de diversas áreas, da arte, da filosofia, da história, pois essas são primordiais para a formação do homem livre e universal. 
Na pergunta final "Em sua opinião, qual conhecimento de mundo esses leituras digitais te proporcionam?”, as respostas obtidas foram expostas no quadro 1:

Quadro 1: Conhecimento de mundo proporcionado aos universitários pela leitura digital

\begin{tabular}{|l|l|}
\hline E1 & Muito, nos faz ter um grande aprendizado \\
\hline E2 & Sobre o que acontece nos lugares e relação de proximidade pela comunicação acessível e próxima \\
\hline E3 & Conteúdo, conhecimento sobre as vivências da minha futura profissão, musica que uso como hobbie. \\
\hline E4 & $\begin{array}{l}\text { Os artigos me proporciona um conhecimento aplicado em minha área e também o que há de novo. As } \\
\text { notícias me proporcionam um conhecimento geral sobre o mundo e as atualidades }\end{array}$ \\
\hline E5 & $\begin{array}{l}\text { Me informa sobre o que acontece no mundo, me mantem atualizado, isso e importante nos dias de } \\
\text { hoje. }\end{array}$ \\
\hline E6 & Mantenho atualizado \\
\hline E7 & Bastante conhecimento científico pela quantidade de materiais disponíveis \\
\hline E8 & $\begin{array}{l}\text { Conhecimentos sobre minha profissão e as formas de atuação que vou ter mais pra frente, ou seja, me } \\
\text { atualiza sobre isso }\end{array}$ \\
\hline E9 & Me faz aprender a saber sobre o mundo, os lugares e as pessoas \\
\hline E10 & A leitura de um mundo atual, mostrando o que há de novo \\
\hline
\end{tabular}

Fonte: Elaboração própria.

Constata-se que $70 \%$ dos participantes relataram de alguma forma que as leituras digitais proporcionam uma atualização, seja sobre o mundo, a profissão ou lugares. Sabese que em cada geração tecnológica, as linguagens, que são signos, mediaram o tempo de formas distintas. De leitor contemplativo o homem passou a leitor ativo, trazendo consigo todas as mediações culturais, tecnológicas e midiáticas até então vividas, sem que uma geração tecnológica tenha excluído a outra (LEVY, 2010).

Como já mencionado, todos os estudantes deste estudo leem materiais científicos e outros conteúdos do meio digital, desde notícias sobre sua atuação profissional até vida de famosos, e metade deles afirmam discutir de alguma forma o que leem. No entanto, ao analisar o conhecimento de mundo que têm por intermédio das leituras digitais, nenhum estudante demonstra uma compreensão sobre a realidade na qual ele está inserido para além da atualização do que acontece mundialmente ou na futura profissão, assim como há a ausência de um conhecimento de mundo crítico no sentido de compreender as relações nas quais está inserido, que impulsione a busca por transformação naquilo que ainda não permite ao homem produzir-se de modo a se apropriar dos bens culturais e de superar as desigualdades. 
Nesse sentido, cabe ponderar a necessidade de analisar não apenas o conteúdo da leitura digital ou os recursos tecnológicos, pois estes cumprem seu papel na maioria das vezes em relação ao acesso, facilidade e qualidade. Como ressalva Corrêa (2006, p. 44), “[...] inovações tecnológicas não significam inovações pedagógicas”. Portanto, são necessárias discussões sobre os processos de ensino e aprendizagem em meio às novas possibilidades de pensamento, de vida social, e de relações.

\section{Considerações finais}

O presente estudo teve como objetivo principal analisar qual conhecimento de mundo a leitura na internet proporciona aos universitários. Dez estudantes responderam a um questionário semiestruturado com seis questões sobre suas leituras digitais e o conhecimento de mundo que eles adquirem por intermédio delas. Os dados coletados foram submetidos a uma análise crítica e dialética.

Os resultados coincidem com alguns dos dados da última pesquisa Retratos e Leituras do Brasil, de 2016. Assim como a maioria dos brasileiros, os estudantes da pesquisa leem na internet conteúdos das redes sociais, blogs, notícias e informações, e também pouco a utilizam para realizar leitura de livros, revistas e jornais.

Acerca do material lido na internet, $100 \%$ dos participantes mencionou conteúdos acadêmicos, o que trouxe uma aparência positiva, pois o conhecimento científico que oportuniza um conhecimento de mundo ampliado também é objetivado em materiais acadêmicos. Entretanto, a essência expressa pelos universitários é superficial frente à especificidade da educação e do ato de ler no suporte tela, não permitindo uma ampliação, na visão materialista histórica e dialética, do conhecimento de mundo.

A fim de que o processo educativo exerça seu papel na universidade, a leitura digital, assim como a impressa, deve superar a mera contemplação, a leitura e decodificação de códigos e a memorização para avaliações acadêmicas. Para tanto, uma possibilidade é que os materiais lidos pelos universitários abrangessem aqueles em que a essência seja repleta de produção humana, de objetivação de conhecimentos históricos, de dimensões - sociais, econômicas, culturais, etc - que desvelem a realidade e despertem a necessidade de transformação. Essa atividade leitora permite ao leitor partir de sua consciência em si em direção à consciência para si. Em outras palavras, a atividade leitora 
humanizadora é para além da autoconsciência, pois possibilita a formação humana com o conhecimento de mundo crítico, reflexivo e transformador.

\section{REFERÊNCIAS}

ALTOÉ, A. Formação de professores para o uso do computador em sala de aula. Teoria e prática da educação. Maringá: DTP/UEM, v. 6, n. 14, p. 483-496, edição especial, 2003.

CORRÊA, J. Novas tecnologias da informação e da comunicação; novas estratégias de ensino/ aprendizagem. In: COSCARELLI, C. V. Novas tecnologias, novos textos, novas formas de pensar. Belo Horizonte: Autêntica, 2006.

GIROUX, H. A. Os professores como intelectuais. Porto Alegre: Artes Médicas, 1997.

LALUEZA, J. L.; CRESPO, I.; CAMPS, S. As tecnologias da informação e da comunicação e os processos de desenvolvimento e socialização. In: Coll, C., Monereo, C. Psicologia da educação virtual: aprender e ensinar com as tecnologias da informação e comunicação, p. 47-65, 2010.

LEMOS, A. Cibercultura, tecnologia e vida social na cultura contemporânea. Porto Alegre: Sulina. 2010.

LEVACOV, M. Do Analógico ao Digital: A comunicação e a Informação no Final do Milênio. In: LEVACOV, M. et. al. Tendências na Comunicação. Porto Alegre: L\&PM, 1998.

LEVY, P. Cibercultura. Editora 34, 2010.

MANGUEL, A. Uma história da leitura. São Paulo: Companhia das Letras, São Paulo: Companhia das Letras, 1997.

NETO, J. C. M. Retratos da leitura no Brasil e políticas públicas: fazer crescer a leitura na contracorrente - revelações, desafios e alguns resultados. In: FAILLA, Zoara. Retratos da Leitura no Brasil 4. p.57-73, Rio de Janeiro: Sextante, 2016.

OLIVEIRA, F. R. Práticas de Comunicação e desenvolvimento cognitivo na cibercultura. Intexto, n. 25, p. 128-143, 2011.

SÁNCHEZ GAMBOA, S. Os projetos de pesquisa: alguns fundamentos lógicos necessários. In: MIRANDA, E.; PACIULLI BRYAN, N.; (editores). (Re)pensar la educación pública: aportes desde Argentina y Brasil, Córdoba: Ed Universidad Nacional de Córdoba, p. 121-150, 2010.

SANTOS, E. Educação online para além da EAD: Um fenômeno da Cibercultura. Actas do $X$ Congresso Internacional Galego-Português de Psicopedagogia. Braga: Universidade do Minho, 2009. 
SAVIANI, Dermeval. Pedagogia histórico-crítica: primeiras aproximações. Autores associados, 42 $2^{\mathrm{a}}$ ed. 2013.

VIGOTSKI, L. S. A formação social da mente. 7 ed. São Paulo: Martins Fontes, 2007.

WEBER, A; SANTOS, E; DA CRUZ, M. M. Letramentos e alfabetizações na cibercultura: crianças e jovens em rede, desafios para educação. Leitura: Teoria \& Prática, v. 32, n. 62, p. 59-73, 2014.

\section{Como referenciar este artigo}

NASCIMENTO, Francielle Pereira.; FRANCO, Sandra Aparecida Pires. Conhecimento de mundo por meio da leitura digital: um estudo com universitários. Revista IberoAmericana de Estudos em Educação, Araraquara, v. 12, n. esp. 2, p. 1511-1523, ago./2017. Disponível em: <http://dx.doi.org/10.21723/riaee.v12.n.esp.2.10306>. E-ISSN: 1982-5587.

Submetido em: 20/04/2017

Aprovação final em: 10/08/2017 